\title{
Synthesis of bio-based thermoplastic polyurethane elastomers containing isosorbide and polycarbonate diol and their biocompatible properties
}

\author{
So-Yeon $\mathrm{Oh}^{1}$, Min-Sil Kang ${ }^{1}$, Jonathan C Knowles ${ }^{2}$ and Myoung-Seon Gong ${ }^{1}$ \\ ${ }^{1}$ Department of Nanobiomedical Science and BK21 PLUS NBM Global Research Center, \\ Dankook University Graduate School, Chungnam, South Korea \\ ${ }^{2}$ Division of Biomaterials and Tissue Engineering, UCL Eastman Dental \\ Institute, University College London, London, UK
}

\begin{abstract}
A new family of highly elastic polyurethanes (PUs) partially based on renewable isosorbide were prepared by reacting hexamethylene diisocyanate with a various ratios of Is and polycarbonate diol 2000 (PCD), via a one-step bulk condensation polymerization without catalyst. The influence of the isorsorbide/PCD ratio on the properties of the polyurethane was evaluated. The successful synthesis of the polyurethanes was confirmed by Fourier transform-infrared spectroscopy and ${ }^{1} \mathrm{H}$ nuclear magnetic resonance. The resulting PUs showed high number-average molecular weights ranging from 56,320 to $126,000 \mathrm{~g} \mathrm{~mol}^{-1}$ and tunable $\mathrm{Tg}$ values from -34 to $-38^{\circ} \mathrm{C}$. The thermal properties were determined by differential scanning calorimetry and thermogravimetric analysis. The PU films were flexible with breaking strains from $955 \%$ to $1795 \%$ at from 13.5 to $54.2 \mathrm{MPa}$ tensile stress. All the polyurethanes had $0.9-2.8 \%$ weight lost over 4 weeks and continual slow weight loss of 1.1 $3.6 \%$ was observed within 8 weeks. Although the cells showed a slight lower rate of proliferation than that of the tissue culture polystyrene as a control, the polyurethane films were considered to be cytocompatible and nontoxic. These thermoplastic polyurethanes were soft, flexible and biocompatible polymers, which open up a range of opportunities for soft tissue augmentation and regeneration.
\end{abstract}


Keywords: Isosorbide; Polyurethane; Thermoplastic elastomer; Biocompatibility; poly(carbonate diol)

\section{Introduction}

Elastomers can undergo varying degrees of deformation under stress without rupture, and recover to their original state when the stress is removed, as described earlier. Elastomers can be divided into two categories: physically crosslinked elastomers and chemically crosslinked elastomers [1]. The flexible polymer chains of physically crosslinked elastomers are held together by weak hydrogen bonds, dipolar forces, crystalline regions or by glassy domains. The majority of thermoplastic elastomers usually possess a segmented structure with two separated microphases, which consists of a soft segment and a hard segment. The hard segments function as crosslinkers which provide mechanical strength, whereas amorphous segments provide the flexibility [2].

Polyurethane (PU) has been applied in a variety of application such as flexible and rigid foam, elastomer and textile. Recently development of biocompatible PU has come into the spotlight because these polymers were used in a wide range of biomaterial [1]. Durability, elasticity, flexibility, mechanical and physical properties is suitable as a medical biomaterials [3]. It is widely used in medical fields such as scaffold for skin reproduction and drug delivery system, artificial blood vessel and artificial heart [4-6]. Biocompatible PU elastomer comprises two-segment structures in which hard segment of diisocyanate are distributed in a soft segment of polyol. The hydrogen bonds are dipolar forces originated from diisocyanate and the rigid structure also responsible for the crystalline region as hard segment. Bio-based rigid bicyclic diols such as isosorbide and isomannide can play a role as a hard segment. Moreover, such rigid diols impart biocompatible and bioactive properties to thermoplasctic PU elastomers [7-9]. 
Typical polyols are based on polyesters, polyethers, polycarbonates and PUs as a soft segment for amorphous region in high elastic PUs [10-14]. The choice of the diols determines the physical properties of resulting PUs using hexamethylene diisocyanate and isorsobide based chain extender by bulk polymerization [7-9,15-16]. Polyesters are unstable on hydrolysis [4], generating additionally acidic degradation products, while polyethers are hydrolytically stable, but susceptible to oxidation [17]. Oligocarbonate diols, on the contrary, are stable on hydrolysis and resistant to oxidation and so constitute promising soft segments for PUs used for biomedical applications [18-20]. In recent years, PUs based on polycarbonate diol have been studied and exploited in applications. The main disadvantage of polycarbonate PUs as compared with "classical" polyether- or polyester-based PUs is their high cost, but their superior mechanical, biological, heat-, oxidative-, hydrolysis- and UVlight resistant properties usually compensate the cost drawback [21-24]. However, the application potential of PU materials is far from being exploited and therefore detailed studies of the structure-properties relationship of well-defined materials (including details of their preparation) are needed [25].

Isorsobide are bio-based diols, it is the only one possibly produced from starch at the industrial scale. Isorsobide as sugar diols are non-toxic, they demonstrate thermal and chemical stabilities [26]. It contains two cycloaliphatic rings likely to bring a good inflexible to the PU [27].

In this study, we present the synthesis of a new family of biocompatible and bioactive PUs synthesized via simple catalyst-free, one-shot polymerization of hexamethylene diisocyanate, polycarbonate diol 2000 (PCD) and isosorbide. The chemical structure of the resulting thermoplastic PU elastomers was confirmed by Fourier transform-infrared (FT-IR) and ${ }^{1} \mathrm{H}$-nuclear magnetic resonance $\left({ }^{1} \mathrm{H}-\mathrm{NMR}\right)$ spectroscopy, and the physical properties were determined by differential scanning calorimeter (DSC), thermogravimetric analysis 
(TGA) and gel permeation chromatography (GPC). We also evaluated the mechanical properties, degradation rate, and biocompatibility which generally correlated with the ratio of isosorbide to PCD. 


\section{Materials and methods}

\section{Materials}

The aliphatic polycarbonate diol 2000 (T4672, PCD) was purchased from Asahi Kasei Chemical Corporation. PCD was dried under reduced pressure at $60^{\circ} \mathrm{C}$ for $4 \mathrm{~h}$ before use. $N, N$-Dimethylformamide (DMF) and hexamethylene diisocyanate (HDI, supplied by SigmaAldrich (St. Louis, MO, USA) were used as received. 1,4:3,6-Dianhydro- $D$-sorbitol (Isosorbide, 98\%, Sigma-Aldrich, St. Louis, MO, USA) was used after drying at $40^{\circ} \mathrm{C}$ for $6 \mathrm{~h}$ under vacuum. Phosphate buffered saline (approximate $p \mathrm{H}$ 7.3) was obtained from Oxoid Ltd. (Basingstoke, Hampshire, England).

\section{Instruments}

${ }^{1} \mathrm{H}-\mathrm{NMR}$ spectra for the synthesized PUs were recorded with a Bruker Avance 400 spectrometer (400 MHz, Karlsruhe, Getmany) and performed at ambient temperature with 5\% $(\mathrm{w} / \mathrm{v})$ polymer solution in $\mathrm{CDCl}_{3}$. Tetramethylsilane was used as the internal reference. FT-IR spectra were obtained using a Varian 640-IR (Varian Australia Pty., Ltd, Sydney, Australia) in the range of 4000 to $800 \mathrm{~cm}^{-1}$. A $2.5 \%$ solution of polymer in chloroform was deposited directly onto a KBr pellet (Sigma-Aldrich (St. Louis, MO, USA). Subsequent evaporation of chloroform at $50^{\circ} \mathrm{C}$ under vacuum was performed for $2 \mathrm{~h}$. The spectra did not show evidence of residual solvent. The weight average $(\mathrm{Mw})$ and number average $(\mathrm{Mn})$ molecular weights of the PUs were measured by GPC using a FUTECS NP-4000 instrument (Futecs Co. LTD, Seoul, South Korea) equipped with a model P-4000 pump, a model AT-4000 column oven, GPC (KF-802, KF-804 and KF-805) columns, and a Shodex (Shodex, Yokohama, Japan) R1101 refractive index detector. Tetrahydrofuran (THF) was used as the eluent at a flow rate of $1.0 \mathrm{~mL} / \mathrm{min}$, and a sample concentration of $2.5 \mathrm{mg} / \mathrm{mL}$ was used. Polystyrene $(\mathrm{Mw}=2000$, 
$7000,12,000,65,000$, and 120,000) was used as the standard. DSC data were recorded with a DSC (SEIKO Exstar 7020, Tokyo, Japan) instrument. Specimens ( $\sim 10 \mathrm{mg})$ were sealed in a DSC Al pan before being placed in the calorimeter, cooled to $-70^{\circ} \mathrm{C}$, and then heated to $300^{\circ} \mathrm{C}$ at a rate of $10^{\circ} \mathrm{C} / \mathrm{min}$ using a nitrogen atmosphere. TGA tests were conducted on the samples using Shimadzu TGA 50 (Shimadzu, Tokyo, Japan) equipment operating from $30^{\circ} \mathrm{C}$ to $600^{\circ} \mathrm{C}$ at a heating rate of $10^{\circ} \mathrm{C} / \mathrm{min}$ and under a nitrogen atmosphere. Tensile strength and elongation at break of the PUs were measured on an Instron universal testing machine (Model 3344, Instron Engineering Corp., Canton, MA, USA) at a crosshead speed of $10 \mathrm{~mm} / \mathrm{min}$ at room temperature. Polymer films were prepared by solvent casting in DMF at a $10 \%$ polymer concentration followed by air drying to give films of $0.2 \mathrm{~mm}$ thickness. The samples of polyurethane film were cut in dumbbell shape. The results reported are the mean values for five replicates an experiment. The wettability of the polymer surface was evaluated based on contact angle measurements using PHX 300 contact angle equipment (S.E.O, Seoul, Korea). The surface energy calculation was carried out using the Girifalco-Good-Fowkes-Young method via PHX software. Scanning electron microscopic (SEM) photographs were obtained using a SEM (Model JSM-5410LV, JEOL, Tokyo, Japan) at a magnification of 1000x or 1500x.

\section{Synthesis of polyurethanes}

In a four-necked round-bottomed flask equipped with a mechanical stirrer, thermometer, and condenser, polycarbonate diol $(25.0 \mathrm{mmol}, 50 \mathrm{~g})$ and isosorbide $(25.0 \mathrm{mmol}, 4.78 \mathrm{~g})$ (reactant stoichiometry and precursor weight are given as an example for PU1; Table 1) were charged at $80^{\circ} \mathrm{C}$ for $1 \mathrm{~h}$ under a dry nitrogen atmosphere. After the solid contents were melted thoroughly, hexamethylene diisocyanate (HDI, $52.5 \mathrm{mmol}, 6.09 \mathrm{~g}$ ) was added and stirred for 5 min with a nitrogen flush. The reaction mixtures were allowed to stand in a Teflon beaker 
to polymerize for $12 \mathrm{~h}$ at $120^{\circ} \mathrm{C}$. The synthesized PUs were dissolved in (DMF). After the resulting PU solution was poured into a large amount of isopropyl alcohol and filtered, and washed with methanol. The PU product was dried at $50^{\circ} \mathrm{C}$ for $24 \mathrm{~h}$ under vacuum and stored in a desiccator. Other PUs with a different content of PCD and isosorbide were prepared using a similar procedure. Polyurethane films for mechanical testing and degradation testing were prepared by solvent casting. Dried PU powder (10 g) was dissolved in DMF (90 g) at room temperature. The polymer solution $(10 \mathrm{w} \%$ concentration) was spread on a casting surface made of polytetrafluoroethylene (PTFE) and allowed to dry for $24 \mathrm{~h}$ at $50^{\circ} \mathrm{C}$ in order to realize DMF evaporation. The final PU films were dried under vacuum at $50^{\circ} \mathrm{C}$ to produce films with $0.20 \pm 0.02 \mathrm{~mm}$ thickness.

\section{In vitro degradation test}

The PU film (Diameter $=25 \mathrm{~mm})$ degradation was quantified by changes in dry weight. The PU samples were degraded for 2,4 , and 8 weeks. The dry films were weighed $\left(\mathrm{W}_{0}\right)$ and immersed in sealed sterile plastic Eppendorf tubes containing phosphate-buffered saline (10 $\mathrm{mL}$, approximate $\mathrm{pH}=7.3$ ). The degradation was conducted at $37 \pm 1.5^{\circ} \mathrm{C}$ in a water-bath (Daihan WiseBath, Seoul, Korea). Samples were taken at intervals, rinsed with water, dried in a vacuum oven for 2 days at $50^{\circ} \mathrm{C}$, and weighed $\left(\mathrm{W}_{\mathrm{t}}\right)$, after which they were discarded. The remaining weight was calculated as: Weight remaining $(\%)=\mathrm{W}_{0}-\mathrm{W}_{\mathrm{t}} / \mathrm{W}_{0}$

\section{Cell culture}

The PU films were sterilized by soaking them in 50, 70, and $100 \%$ ethanol for 30 min prior to use and then they were dried for $2 \mathrm{~h}$. MC3T3-E1 cells were maintained in standard T75 tissue culture flasks in normal growth medium composed of $\alpha$-modified minimum essential medium 
(Invitrogen, Paisley, UK) supplemented with 10\% fetal bovine serum (Gibco, Daejeon, South Korea) and 1\% penicillin/streptomycin (Gibco). Prior to cell seeding, sections were cut from the synthesized PU films. MC3T3-E1 cells were suspended at $5 \times 10^{3}$ cells $/ \mathrm{mL}$ concentration in normal growth medium. A $1 \mathrm{~mL}$ aliquot of the cell-containing medium was seeded onto each 96 well plate containing films of PU with different isosorbide and PCD concentration and maintained at $37^{\circ} \mathrm{C}$ in $5 \% \mathrm{CO}_{2}$ for a subsequent time course analysis of cell number.

\section{Cell proliferation}

Cells were cultured on the PU films (the films were held down on the bottom of the plates with polytetrafluoroethylene insert rings) in 96-well plates for 1, 3, and 7 days. Cell proliferation was determined at these times using the Cell Counting kit-8 (CCK-8, 2(methoxy-4-nitrophenyl)-3-(4-nitrophenyl)-5-(2,4-disulfophenyl)-2H-tetrazolium monosodium salt) assay, according to the manufacturer's instructions (Dojindo Laboratories, Kumamoto, Japan). Cell number was measured using the CCK-8 reagent. The CCK-8 solution was freshly prepared in growth medium, and $200 \mu \mathrm{L}$ of CCK-8 reagent was added to each well, followed by incubation in a humidified atmosphere with $5 \% \mathrm{CO}_{2}$. Absorbance was measured at $450 \mathrm{~nm}$ using a spectrophotometer (Bio-Rad, Seoul, South Korea). A blank experiment to detect cell-free background absorbance was also performed in parallel. Results are expressed as relative CCK-8 activity compared to control conditions. 


\section{Results and discussion}

Preparation of high elastic polyurethane

Our one-pot polymerization process is very simple and reduces the risk of toxicity from a surfactant or catalyst. Polymerizations of HDI and diols with varying ratio of PCD to isosorbide were carried out by one-pot polymerization via addition-condensation reaction without catalyst as shown in Figure 1. The optimal ratios of PCD to isosorbide were determined by consideration for elastic behaviors of PUs [7-9]. The ratios of PCD to isosorbide were PCD/isosorbide $=5 / 5,4 / 6,3 / 7$ and 2/8. Miscibility of isosorbide in PCD and HDI was low, assuming that the isosorbide was hydrophobic than those of PCD and HDI. Thus, the polymerizations of HDI with various mole ratios of PCD to isosorbide were carried out after premixing solution of three monomers at $80^{\circ} \mathrm{C}$. Finally the polymerizations were performed at $120^{\circ} \mathrm{C}$ for $12 \mathrm{~h}$. The results of the polymerizations are summarized in Table 1 .

$<$ Figure $1><$ Table $1>$

The solubility of the PUs was investigated using various common organic solvents. With an increasing ratio of isosorbide to PCD, the solubility gradually decreased in chloroform. The polymers were soluble in polar aprotic solvents such as $N$-methylpyrrolidon, DMF and dimethyl sulfoxide but insoluble in THF, toluene and ethanol. PU4 had higher content of rigid bicyclic isosorbide linkages, which possibly caused the lack of solubility in solvent.

The thermal properties and molecular weights of the PUs are listed in Table 2. The weight average molecular weights (Mw) ranged from 106,786 to 196,300. PUs with higher content of isosorbide may have yielded lower molecular weights than those of PUs with low isosorbide content due to a large content of secondary hydroxyl group, which had lower reactivity to isocyanate than that of the primary hydroxyl group of PCD [28]. 
In the FT-IR spectra, the characteristic peak of cumulated diene $-\mathrm{N}=\mathrm{C}=\mathrm{O}$ in $\mathrm{HDI}$ at 2254 $\mathrm{cm}^{-1}$ was identified as shown in Figure 2. After polymerization, the peak was completely disappeared. A broad N-H stretching and bending bands of amide group appeared at 3324 $\mathrm{cm}^{-1}$ and $1531 \mathrm{~cm}^{-1}$, respectively. The absorption peaks around 1736 and $1690 \mathrm{~cm}^{-1}$ were from asymmetric and symmetric stretching of the amide carbonyl group, respectively. The IR spectra of PU1, PU2, PU3 and PU4 showed differences between the intensity of ether combination absorption band around 2928 and $2855 \mathrm{~cm}^{-1}$, indicating that the ratio of isosorbide to PCD influenced the intensity of the $\mathrm{C}-\mathrm{H}$ stretching and carbonyl bands. In addition, the peaks around 1736 (carbonate $\mathrm{C}=\mathrm{O}$ ) $\mathrm{cm}^{-1}$ were gradually stronger, which was due to an increased amount of PCD. At the same time, the peak around $3324 \mathrm{~cm}^{-1}$ also decreased with decreasing molar ratio of isorsobide.

$<$ Figure 2 $>$

Figure 3(a) displays the ${ }^{1} \mathrm{H}$ NMR spectrum of the PU4 with $\mathrm{PCD} /$ isosorbide $=2 / 8$, in which all proton signals of isosorbide, PCD, and the HDI segments (Figure 3(b)) were confirmed. The peaks occurring between 3.50 and $5.01 \mathrm{ppm}$ were assigned to the bicyclic methylene protons of isosorbide. In addition, the peak at 7.65 ppm was assigned to the amine proton of the urethane N-H moiety. Signals occurring at 1.40, 1.65, and 3.28 ppm could be reasonably assigned to methylene protons of the HDI moiety. The alkylene protons of PCD were observed at $1.65,1.55$ and $4.10 \mathrm{ppm}$.

$<$ Figure $3>$

Much attention has been paid to the surface structure and property of polymeric materials, because the functional groups on the surface play an important role in the interactions among materials with biological molecules and cells [29,30]. As shown in Table 2 , most of the PUs showed water contact angles $<57^{\circ}$. It is generally agreed that hydrophilic 
surfaces possess contact angles with water in the range $1-30^{\circ}$ and those of hydrophobic surfaces are $>90^{\circ}$. Thus, the polymers presented here showed values somewhere between these ranges. The surface hydrophobicity of the PUs with different isosorbide content and PCD segments was characterized by static water contact angle measurements. As shown in Table 2, an increase in the isosorbide moiety in the PUs decreased the contact angles slightly from $57^{\circ}$ to $50^{\circ}$, which improved the hydrophilic nature of the PU surfaces.

\section{Thermal properties.}

It is important to understand the thermal behavior of PUs developed for biomedical applications, as it determines the physical properties of the materials and the processability. Differential scanning calorimetry (DSC) and thermogravometric analysis (TGA) were used to characterize the thermal behaviors of the PUs in this experiment. The DSC and TGA data are summarized in Table 2. In their DSC curves, a weak broad endothermic peak of between $60^{\circ} \mathrm{C}$ and $70^{\circ} \mathrm{C}$ for all PUs were caused by melting transition of crystal domain in thermoplastic elastomeric feature as observed in Figure 4(a). The glass transition temperature $\left(\mathrm{T}_{\mathrm{g}}\right)$ for PU1, PU2, PU3 and PU4 were $-33.9,-36.1,37.2$ and $-37.9^{\circ} \mathrm{C}$, respectively, which are higher than those of poly(tetramethylene glycol)-based Pus [31]. The variations in the $\mathrm{T}_{\mathrm{g}}$ of the soft segment as a function of composition have been suggested as an indicator of the degree of microphase separation in thermoplastic PU elastomers [32]. Factors with an effect on $\mathrm{T}_{\mathrm{g}}$ in PUs based on aliphatic diisocyanate include crystallization between soft-segment and hard-segment components, the steric hindrance of the hard-segment unit during hydrogen bonding, and the inherent solubility of the hard and soft components [33]. For the PUs in this study, the $\mathrm{T}_{\mathrm{g}}$ slightly decreased with increasing contents of PCD. Thus all PUs had a similar $\mathrm{T}_{\mathrm{g}}$. These PUs could exhibit elastomeric properties at body temperature. If the $\mathrm{T}_{\mathrm{g}}$ value is above body temperature, material will be in a rigid state. 
All PUs showed a one-stage decomposition in the TGA thermograms, which was due to the existence of all alkylene units. The TGA curves for the four PUs nearly overlapped and began to lose $10 \%$ and $90 \%$ weight around 300 and $340^{\circ} \mathrm{C}$, respectively, in nitrogen as shown in Figure 4(b). It can be seen that the temperatures of $10 \%$ weight loss of the PUs decreased from $308^{\circ} \mathrm{C}$ to $290^{\circ} \mathrm{C}$ as isosorbide content decreased, suggesting that all PUs were thermally stable and could tolerate sterilization.

$<$ Figure 4 (a) DSC, Figure 4 (b) TGA, Table 2>

\section{Mechanical properties}

Elastomeric properties at body temperature are an important quality for biocompatible polymers in soft tissue engineering [34]. The tensile properties i.e., Young's modulus, ultimate tensile strength (UTS) and strain at break were evaluated. Tensile properties for PUs are given in Figure 5. PU1 with highest isosorbide content showed Young's modulus of 43.68 $\pm 4.32 \mathrm{MPa}$ compared to $549.27 \pm 15.21 \mathrm{MPa}$ for the PU4. The UTS was from $54.26 \pm 1.03$ to $13.56 \pm 1.72 \mathrm{MPa}$ for PU1 and PU4. The PU4 with the lowest isosorbide content produced a tensile strength of $13.56 \pm 1.72 \mathrm{MPa}$. The PU films were flexible with breaking strains from $955 \%$ to $1795 \%$. As can clearly be seen from the data, increase in isosorbide content increased the UTS. The UTS of the films was comparable to that of the aorta $(50 \%-100 \%)$ [35], whereas the breaking strains were generally greater than that of the aorta.

The mechanical properties of the film depended on the molecular weight, hard segments, and soft segments. As the molecular weight of a polymer increases, tensile strength increased. In addition, there was a relationship between hard segment and stiffness [35]. The stiffness increased with increasing isosorbide hard segment content. The main degradable polymers used in biomedicine are polycaprolacton, polyglycolic acid, poly(L-lactic acid) and their derivatives. These polymers are all very stiff and are not suitable for utilization for tissue 
engineering of soft tissues, even in a fibrous or woven state. The development of softer, more flexible, and degradable polymers, as shown in this study, opens up a range of opportunities for soft tissue augmentation and regeneration, and the polymer family synthesized in this study offers such properties.

$<$ Figure 5 $>$

\section{In vitro degradation test}

The degradation behaviors of PU1, PU2, PU2 and PU4 were evaluated in vitro. The degradation rates of the three PU samples performed in a phosphate buffer solution at $37^{\circ} \mathrm{C}$ were shown in Figure 6 . The PU3 showed fast weight loss with $5 \mathrm{wt} \%$ of initial weight lost within 8 weeks. The changes in the PU film surface after degradation were determined by scanning electron microscope photographs as shown in Figure 7. All surfaces appear relatively smooth initially with a few defects. However, all the PUs had $0.8-2.5 \%$ weight lost over 2 weeks. A continual slow weight loss of 1.5-2.5\% was observed between 2 and 8 weeks. Degradation of aliphatic ester and carbonate bonds in urethanes in aqueous media are well known to be susceptible to hydrolysis [36]. The biodegradability of PUs also depends on the molecular weight, degree of crystallinity, chemical structure, as well as susceptibility to microbial attack [37]. The susceptibility of PUs to biodegradation lies in soft segment components of the polymer. These segments generally dominate the degradation characteristics of PUs, with higher properties of soft segments tending to correlate with increased degradation rate [38]. The isosorbide gives higher hydrophilicity to the PU segment than that of does PCD unit with haxamethylene moiety, making hydrolytic attack easier. The rate of hydrophilicity and hard-segment contents had a more dominant effect on biodegradation rate rather than crystallinity for the PUs presented here [39]. Generally, it is evident that the PU series was undergoing slow degradation. 
$<$ Figure $6><$ Figure $7>$

\section{Cell attachment}

Many studies have ascertained biocompatibility using the CCK-8 or 3-(4,5-dimethylthiazol-2yl)-5-(3-carboxymethoxyphenyl)-2-(4-sulfophenyl)-2H-tetrazolium (MTS) assay. When cell proliferation on a polymer is maintained for $1-2$ weeks, then the polymer can be considered cytocompatible and biocompatible [37]. MC3T3-E1 cells were used as they are highly sensitive to culture conditions. The cell number was assessed via the CCK-8 assay due to its reliability and sensitivity [40]. Cell attachment was examined with the MTS assay. The ODs at $450 \mathrm{~nm}$ for PU3 were $0.19,0.42$ and 0.95 after 1,3 , and 7 day cultures, indicating that the number of cells on the films had increased significantly. The results of CCK-8 absorbance values for MC3T3-E1 cells adhesion to and proliferation on the PU films compared to that of control are shown in Figure 8. Although the cells showed a lower rate of proliferation than that of the control, the PU films were considered to be cytocompatible and nontoxic. Furthermore, the synthesized PUs had good mechanical strength, thermal stability, cytocompatibility, and biodegradability. Attachment of cells to a material is one of the prerequisites for evaluating biocompatibility for possible utilization in biomedical applications. The morphology of MC3T3-E1 cells after they were cultured on the PU films for 1-7 days was examined by SEM. The SEM images of the MC3T3-E1 cell morphology on PU films during 7 days are shown in Figure 9. The PU films provided a suitable environment for cell attachment and spreading.

$<$ Figure $8><$ Figure $9>$

\section{Conclusion}

Four series of different content of isosorbide and polycarbonate diol based thermoplastic biocompatible PU elastomers were synthesized by a simple one-shot bulk polymerization without catalyst. Depending upon varying the ratio of polycarbonate diol and isosorbide in 
the PUs, a variety of biocompatible PUs with different thermal and mechanical property could be achieved. The resulting PUs showed high number-average molecular weights ranging from 56,320 to $126,000 \mathrm{~g} \mathrm{~mol}^{-1}$ and $\mathrm{T}_{\mathrm{g}}$ values between -34 and $-38^{\circ} \mathrm{C}$. The $\mathrm{PU}$ films were flexible with breaking strains from $955 \%$ to $1795 \%$ at from 13.5 to $54.2 \mathrm{MPa}$ tensile stress. Although the cells showed a slight lower rate of proliferation than that of the control, the PU films were considered to be cytocompatible and nontoxic. These thermoplastic PUs were soft, flexible and degradable polymers, which open up a range of opportunities for soft tissue augmentation and regeneration. These findings suggest that the high elastic PUs obtained biomimetically have high potential to be used as a tissue engineering scaffold and for other biomedical uses.

\section{Conflict of interests}

None declared.

\section{Funding}

This study was conducted by the research fund of Dankook University in 2014. This study was supported by Priority Research Centers Program (no. 2009-0093829) through the National Research Foundation of Korea. 


\section{References}

1. Chena Q, Liang S and Thouas GA. Elastomeric biomaterials for tissue engineering. Prog Polym Sci 2013; 38: 584- 671.

2. Hiki S, Miyamoto M, Kimura Y. Synthesis and characterization of hydroxy-terminated [RS]-poly(3-hydroxybutyrate) and its utilization to block copolymerization with 1-lactide to obtain a biodegradable thermoplastic elastomer. Polymer 2000; 41:7369-7379.

3. Jiang $\mathrm{X}$ and Li J. Synthesis and degradation of nontoxic biodegradable waterborne polyurethanes elastomer with poly(e-caprolactone) and poly(ethylene glycol) as soft segment. Eur Polym J 2007; 43: 1838-1846.

4. Santerre JP, Woodhouse K, Laroche G and Labow RS. Understanding the biodegradation of polyurethanes: from classical implants to tissue engineering materials. Biomater 2005; 26: 7457-70.

5. Zdrahala RJ and Zdrahala IJ. Biomedical applications of polyurethanes: a review of past promises, present realities, and a vibrant future. J of Biomat Appl 1999; 14: 67-90.

6. Zdrahala RJ. Small caliber vascular grafts. Part II: Polyurethanes revisited. J Biomater Appl 1996; 11: 37-61.

7. Lim DI, Park HS, Park JH, Knowles JC and Gong MS. Application of high-strength biodegradable polyurethanes containing different ratios of biobased isomannide and poly( $(\varepsilon-$ caprolactone) diol. J Bioact Compat Polym 2013; 28: 274-288.

8. Park HS, Gong MS and Knowles JC. Catalyst-free synthesis of high elongation degradable polyurethane containing varying ratios of isosorbide and polycaprolactone: Physical properties and initial biocompatibility. J Mater Sci Mater Med 2013; 24: 281-294. 
9. Park HS, Gong MS, et al. Silk fibroin-polyurethane blends: Physical properties and effect of silk fibroin content on viscoelasticity, biocompatibility and myoblast differentiation. Acta Biomater 2013; 9: 8962-8971.

10. Hong Y, Guan JJ, Fujimoto KL, Hashizume R, Pelinescu AL and Wagner WR. Tailoring the degradation kinetics of poly(ester carbonate urethane)urea thermoplastic elastomers for tissue engineering scaffolds. Biomater 2010; 31: 4249-58.

11. Guan JJ, Sacks MS, Beckman EJ and Wagner WR. Biodegradable poly(ether ester urethane)urea elastomers based on poly(ether ester) triblock copolymers and utrescine: synthesis, characterization and cytocompatibility. Biomater 2004; 25: 85-96.

12. Bruin P, Veenstra GJ, Nijenhuis AJ, Pennings AJ. Design and synthesis of biodegradable poly(ester-urethane) elastomer networks composed of non-toxic building-blocks. Macromol Chem Rapid Comm 1988; 9: 589-94.

13. Katarzyna G and Sylwester G. Biodegradable polyurethanes for implants. II. In vitro degradation and calcification of materials from poly( $\varepsilon$-caprolactone)-poly(ethylene oxide) diols and various chain extenders. J Biomed Mater Res 2002; 60: 592-606.

14. Tanaka $\mathrm{H}$ and Kunimura $\mathrm{M}$. Mechanical properties of thermoplastic polyurethanes containing aliphatic polycarbonate soft segments with different chemical structures. Polym. Eng Sci 2002; 42: 1333-1349

15. Krol P. Synthesis methods, chemical structures and phase structures of linear polyurethanes. Properties and applications of linear polyurethanes in polyurethane elastomers, copolymers and ionomers. Prog Mater Sci 2007; 52: 915-1015.

16. Castonguay M, Koberstein JT, Zhang Z and Laroche G. Synthesis, physicochemical and surface characteristics of polyurethanes. Biomedcial applications of polyurethanes. Georgetown, TX: Landies Bioscience, 2001, pp.1021. 
17. Datta $\mathrm{J}$ and Leszkowski K. Investigation of chemical stability of ether-urethane prepolymers. Polimery 2008; 53: 115-119.

18. Resiak I and Rokicki G. Modified polyurethanes for biomedical applications. Polimery 2000; 45: 592-602.

19. Rokicki G, Piotrowska A, Kowalczyk T and Kozakiewicz J. Cyclic carbonates used in the synthesis of oligocarbonate diols involving step growth polymerization. Polimery 2001; 46: $483-493$.

20. Salacinski HJ, Tai NR, et al. In vitro stability of a novel compliant poly(carbonateurea)urethane to oxidative and hydrolytic stress. J Biomed Mater Res 2002; 59: 207-218.

21. Kojio K, Nonaka Y, Masubuchi T and Furukawa M. Effect of the composition ratio of copolymerized poly(carbonate) glycol on the microphase-separated structures and mechanical properties of polyurethane elastomers. J Polym Sci Part B: Polym Phys 2004; 42: 4448-4458.

22. Tanaka $\mathrm{H}$ and Kunimura $\mathrm{M}$. Mechanical properties of thermoplastic polyurethanes containing aliphatic polycarbonate soft segments with different chemical structures. Polym Eng Sci 2002; 42: 1333-1349.

23. Eceiza A, Martin MD, et al.n Thermoplastic polyurethane elastomers based on polycarbonate diols with different soft segment molecular weight and chemical structure: Mechanical and thermal properties. Polym Eng Sci 2008; 48: 297-306.

24. Kultys A, Rogułska M, Pikus S and Skrzypiec K, The synthesis and characterization of new thermoplastic poly(carbonate-urethane) elastomers derived from HDI and aliphaticaromatic chain extendersOriginal Research Article. Eur Polym J 2009; 45: 2629-2643.

25. Špirkova M, Pavličevic J, et al. Novel polycarbonate-based polyurethane elastomers: Composition-property relationship. Eur Polym J 2011; 47; 959-972.

26. Fenouillot-Rimlinger F, Rousseau A, et al. Isosorbide, a green diol for polymers, proceedings of 2010 43rd IUPAC Word Polymer Congress, Glasgow, United Kingdom, 2001. 
27. Besse V, Auvergne R, et al. Synthesis of isosorbide based polyurethanes: An isocyanate free method. React Funct Polym 2013; 73: 588-594

28. Lisa T, Tim GM, Raju A, Francois M, Ranjith J, Ian G and Pathiraja AG. Thermoplastic biodegradable polyurethanes: The effect of chain extender structure on properties and invitro degradation. Biomater 2007; 28: 5407-5417.

29. Gorna K and Gogolewski S. Biodegradable polyurethanes for implants. II. In vitro degradation and calcification of materials from poly(E-caprolactone)-poly(ethylene oxide) diols and various chain extenders. J Biomed Mater Res 2002; 60: 592-606.

30. Cohn D, Stern T, Gonzalez MF and Epstein J. Biodegradable poly(ethylene oxide)/poly(E-caprolactone) multiblock copolymers. J Biomed Mater Res 2002; 59: 273-281. 31. Kim HJ, Kang MS, Knowles JC and Gong MS. Synthesis of highly elastic biocompatible polyurethanes based on bio-based isosorbide and poly(tetramethylene glycol) and their properties. J Biomater Appl 2014; 29: 454-464.

32. Lelah MD and Cooper SL. Polyurethanes in medicine. Boca Raton, FL: CRC Press, 1986.

33. Zhang $\mathrm{C}$, Zhang $\mathrm{N}$ and Wen $\mathrm{X}$. Synthesis and characterization of biocompatible, degradable, light-curable, polyurethane-based elastic hydrogels. J Biomed Mater Res A 2007; 82: $637-650$.

34. Holzapfel GA. Biomechanics of soft tissue. Biomech preprint series, Graz: Institute of Structural Analysis-Computational Biomechanics, Graz University of Technology, Austria, 2000, paper no. 7 .

35. Sharma B, Ubaghs L, Keul H, et al. Synthesis and characterization of alternating poly(amide urethane)s from epsilon-caprolactone, diamines and diphenyl carbonate. Polymer 2005; 46: 1775-1783.

36. Geoghegan M and Krausch G. Wetting at polymer surfaces and interfaces. Prog Polym Sci 2003; 28: 261-302. 
37. Gupta D, Venugopal J, Prabhakaran MP, et al. Aligned and random nanofibrous substrate for the in vitro culture of Schwann cells for neural tissue engineering. Acta Biomater 2009; 5: $2560-2569$.

38. Lamba NMK, Woodhouse KA, Cooper SL. Polyurethanes in biomedicals application, Boca Raton, Fl.; CRC Press, 1998.

39. Gualandi C, Soccio M, Govoni M, et al. Poly(butylene/diethylene glycol succinate) multiblock copolyester as a candidate biomaterial for soft tissue engineering: solid-state properties, degradability, and biocompatibility. J Bioact Compat Polym 2012; 27: 244-264.

40. Koh T, Shinji N, Ryuichiro K, et al. Antitumor activity and macrophage nitric oxide producing action of medicinal herb, Crassocephalum crepidioides. BMC Complement Altern Med 2012; 78: 1-11. 


\section{Figure Captions}

Figure1. Schematic structure of polyurethane synthesized from polycarbonate diol, isosorbide and HDI

Figure 2. FTIR spectra of isosorbide, polyurethane with IS/PCD= 1/1, HDI and PCD.

PCD: polycarbonate diol 2000; IS: isosorbide; HDI: hexamethylene diisocyanate.

Figure 3. ${ }^{1} \mathrm{H}-\mathrm{NMR}$ scan of (a) PU4 with PCD/isosorbide $=2 / 8$ and (b) PCD, isosorbide and hexamethylene diisocyanate.

NMR: nuclear magnetic resonance; PCD: polycarbonate diol 2000.

Figure 4. (a) DSC and (b) TGA thermograms of PCD/IS/HDI polyurethanes with different isosorbide and PCD contents.

PCD: polycarbonate diol 2000; IS: isosorbide; HDI: hexamethylene diisocyanate.

Figure 5. Mechanical properties of thermoplastic polyurethanes: (a) Tensile strain, (b) ultimate tensile strength, (c) strain at breaking and (d) Young's modulus.

Figure 6. In vitro degradation profile of thermoplastic biocompatible polyurethanes as a function of degradation time vs. residual weight.

Figure 7. SEM images illustrating morphology of degradation test on polyurethane films in in phosphate buffer solution during 8 weeks.

Figure 8. CCK assay of rat MC3T3-E1 cultured on polyurethanes wells during the 7 days.

Figure 9. SEM images illustrating morphology of MC3T3-E1 cells after being cultured on polyurethane film at 7 day. 
Table 1. Polyurethanes with different compositions of isosorbide and PCD and their yields.

\begin{tabular}{lllcl}
\hline Polyurethanes & HDI & \multicolumn{4}{c}{ Isosorbide } & PCD $\left(\mathbf{M}_{\mathbf{w}}=\mathbf{2} \mathbf{~ D a} / \mathbf{m o l}\right)$ & Yield $^{\mathbf{a}} \mathbf{( \% )}$ \\
\hline & & \multicolumn{4}{c}{ Mole ratio } \\
PU1 & 10.1 & 5 & 5 & 96.2 \\
PU2 & 10.1 & 6 & 4 & 95.3 \\
PU3 & 10.1 & 7 & 3 & 93.5 \\
PU4 & 10.1 & 8 & 2 & 91.7 \\
\hline
\end{tabular}

HDI: hexamethylene diisocyanate; PCD: polycarbonate diol; ${ }^{\mathrm{a}}$ Yield was measured after reprecipitation from isopropanol. 
Table 2. Molecular weights, thermal properties, and surface energy of the polyurethanes.

\begin{tabular}{|c|c|c|c|c|c|c|}
\hline & $\mathbf{M}_{w}{ }^{a}(K D a) / n$ & $\overline{(K D a) / m}$ & $\mathbf{P D I}^{\mathbf{c}}$ & $\mathbf{T}_{\mathrm{g}}{ }^{\mathrm{d}}\left({ }^{\circ} \mathrm{C}\right)$ & Water $\left({ }^{\circ}\right)^{e}$ & Surface energy $\left(\mathrm{mN} \mathrm{m}^{-1}\right)$ \\
\hline PU1 & 196,300 & 126,000 & 1.56 & -33.9 & $57.31 \pm 1.32$ & $53.61 \pm 1.28$ \\
\hline PU2 & 163,400 & 97,000 & 1.68 & -36.1 & $54.54 \pm 0.96$ & $56.52 \pm 1.12$ \\
\hline PU3 & 121,000 & 78,200 & 1.55 & -37.2 & $51.73 \pm 0.74$ & $59.24 \pm 0.68$ \\
\hline PU4 & 106,786 & 56,320 & 1.90 & -37.9 & $49.98 \pm 0.80$ & $61.37 \pm 0.76$ \\
\hline
\end{tabular}

PDI: polydispersity index.

${ }^{\mathrm{a}}$ The weight average molecular weights.

${ }^{\mathrm{b}}$ The number average molecular weights.

${ }^{c} \mathrm{PDI}=\mathrm{M}_{\mathrm{w}} / \mathrm{M}_{\mathrm{n}}$.

${ }^{\mathrm{d}}$ Glass transition temperature.

${ }^{\mathrm{e}}$ Water contact angle. 


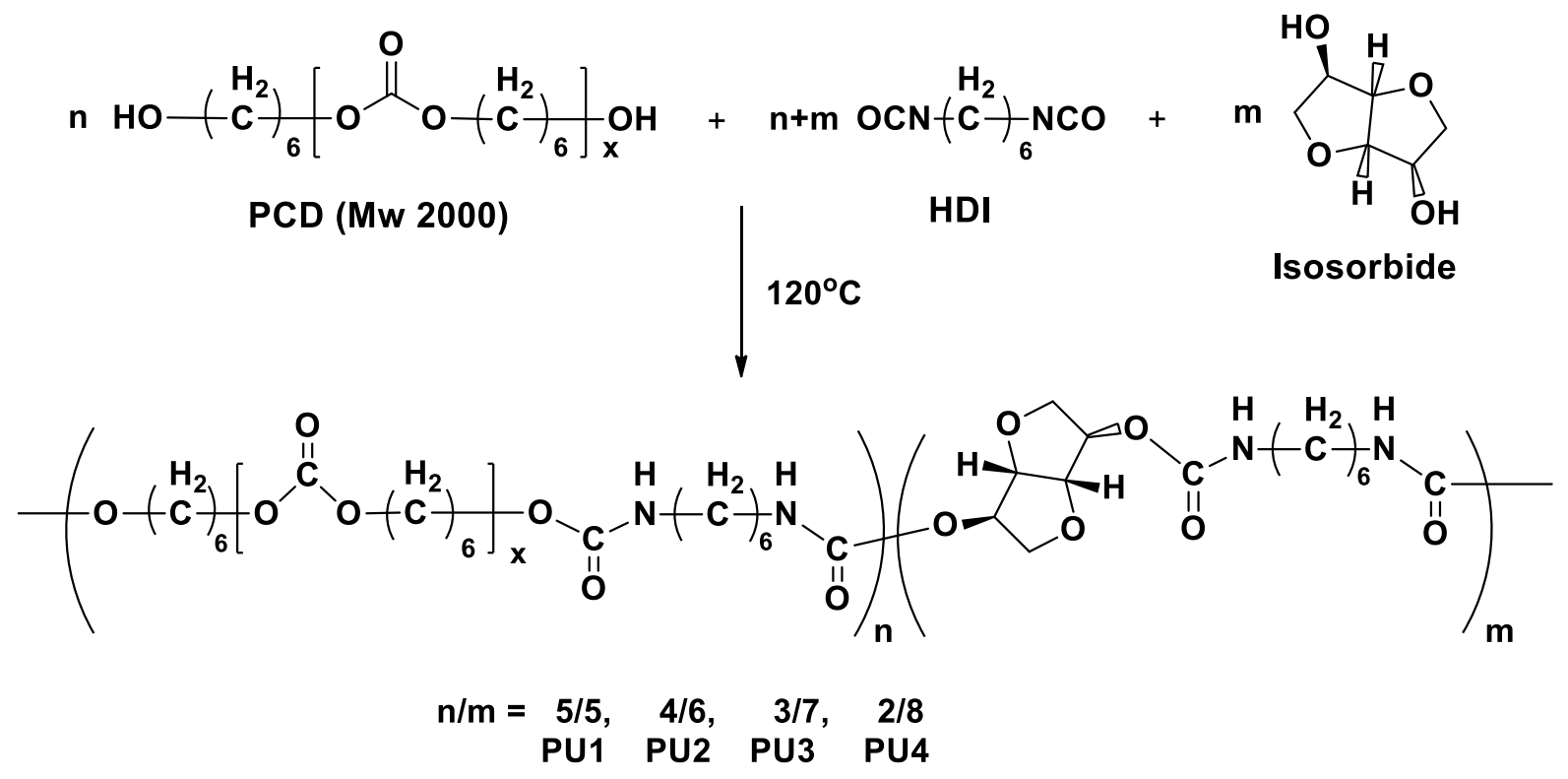

Figure1. Schematic structure of polyurethane synthesized from polycarbonate diol, isosorbide and HDI 


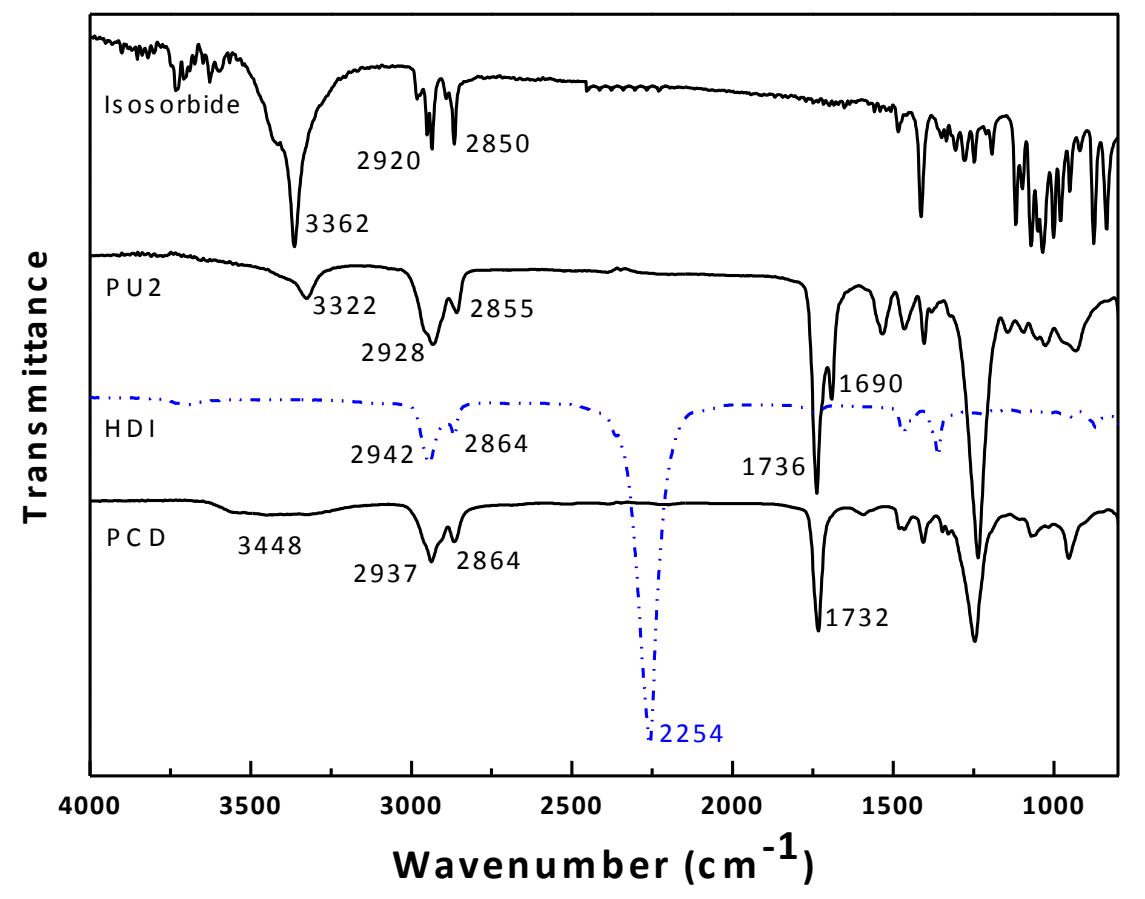

Figure 2. FTIR spectra of isosorbide, polyurethane with IS/PCD $=1 / 1, \mathrm{HDI}$ and PCD. PCD: polycarbonate diol 2000; IS: isosorbide; HDI: hexamethylene diisocyanate. 


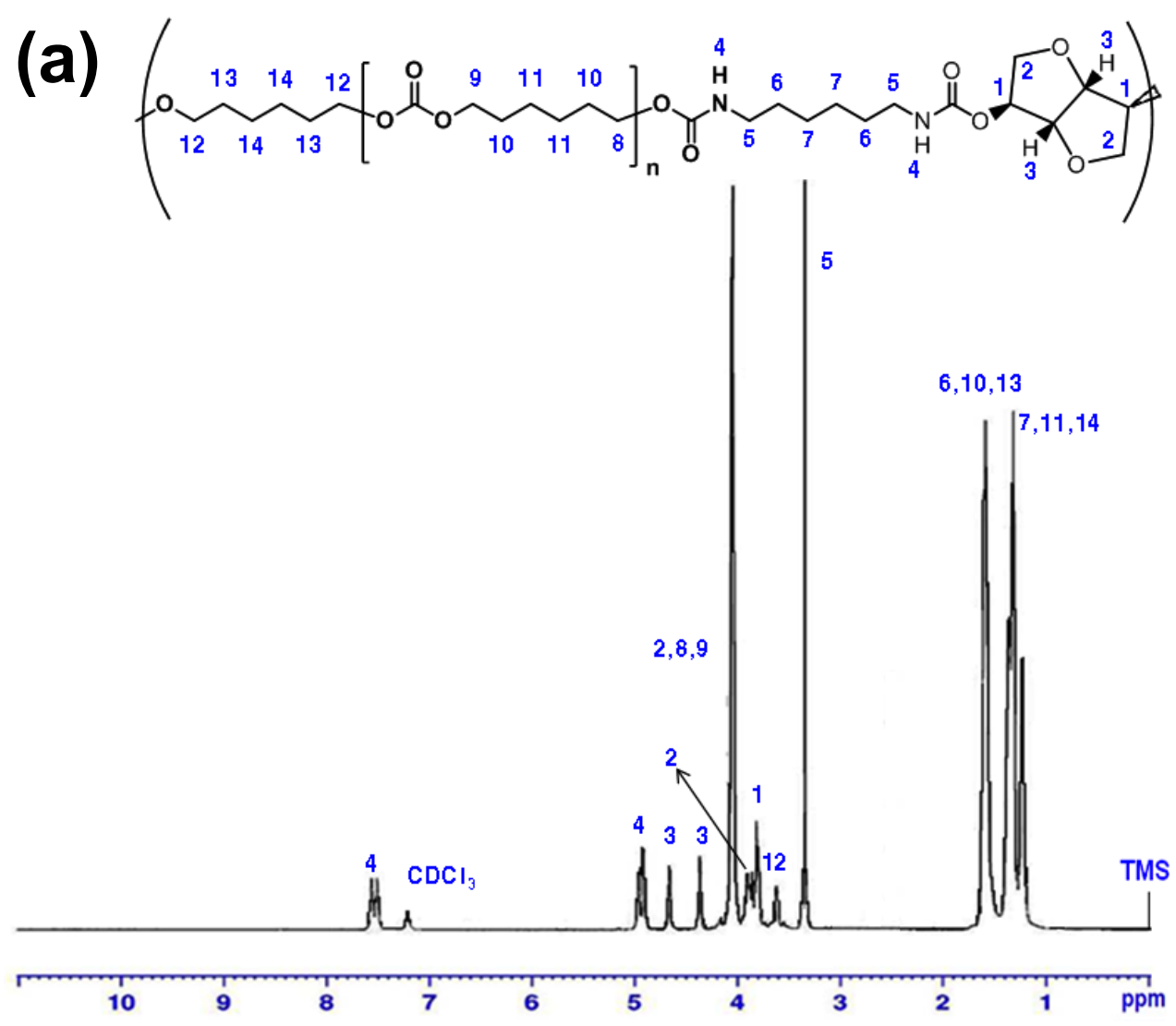

(b)

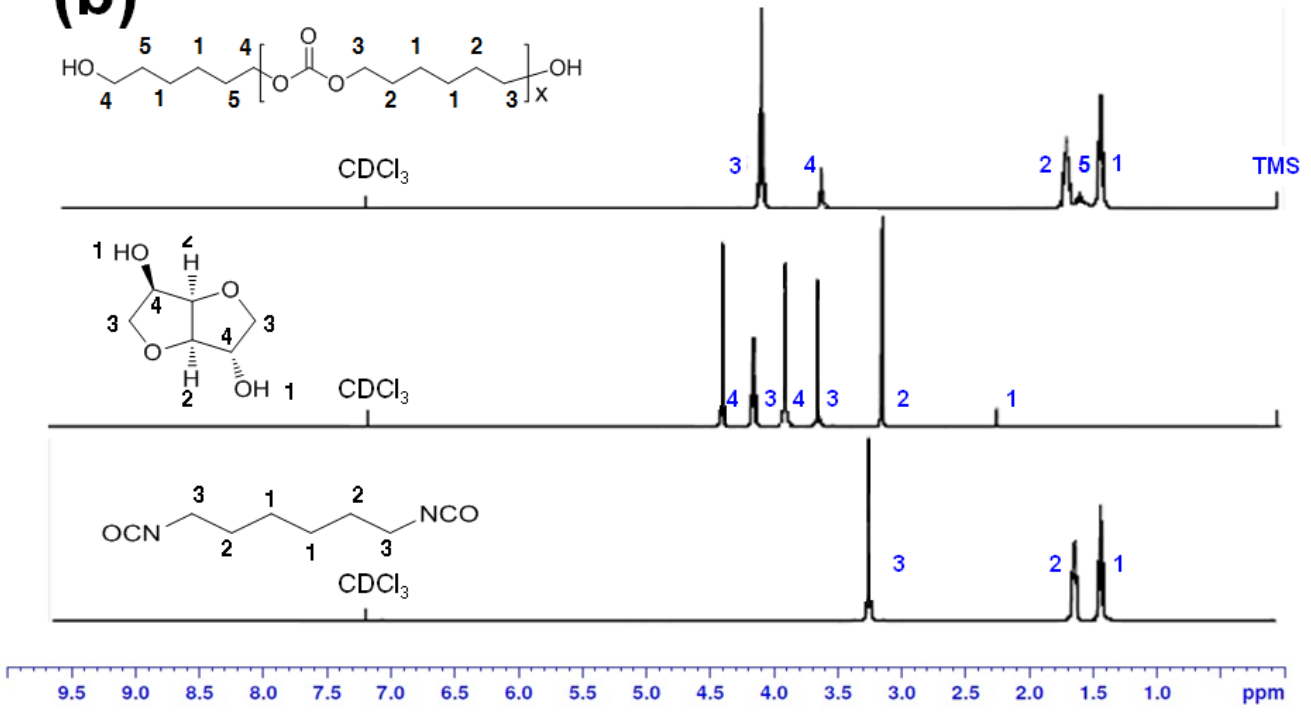

Figure 3. ${ }^{1} \mathrm{H}-\mathrm{NMR}$ scan of (a) PU4 with $\mathrm{PCD} /$ isosorbide $=2 / 8$ and (b) PCD, isosorbide and hexamethylene diisocyanate.

NMR: nuclear magnetic resonance; PCD: polycarbonate diol 2000. 

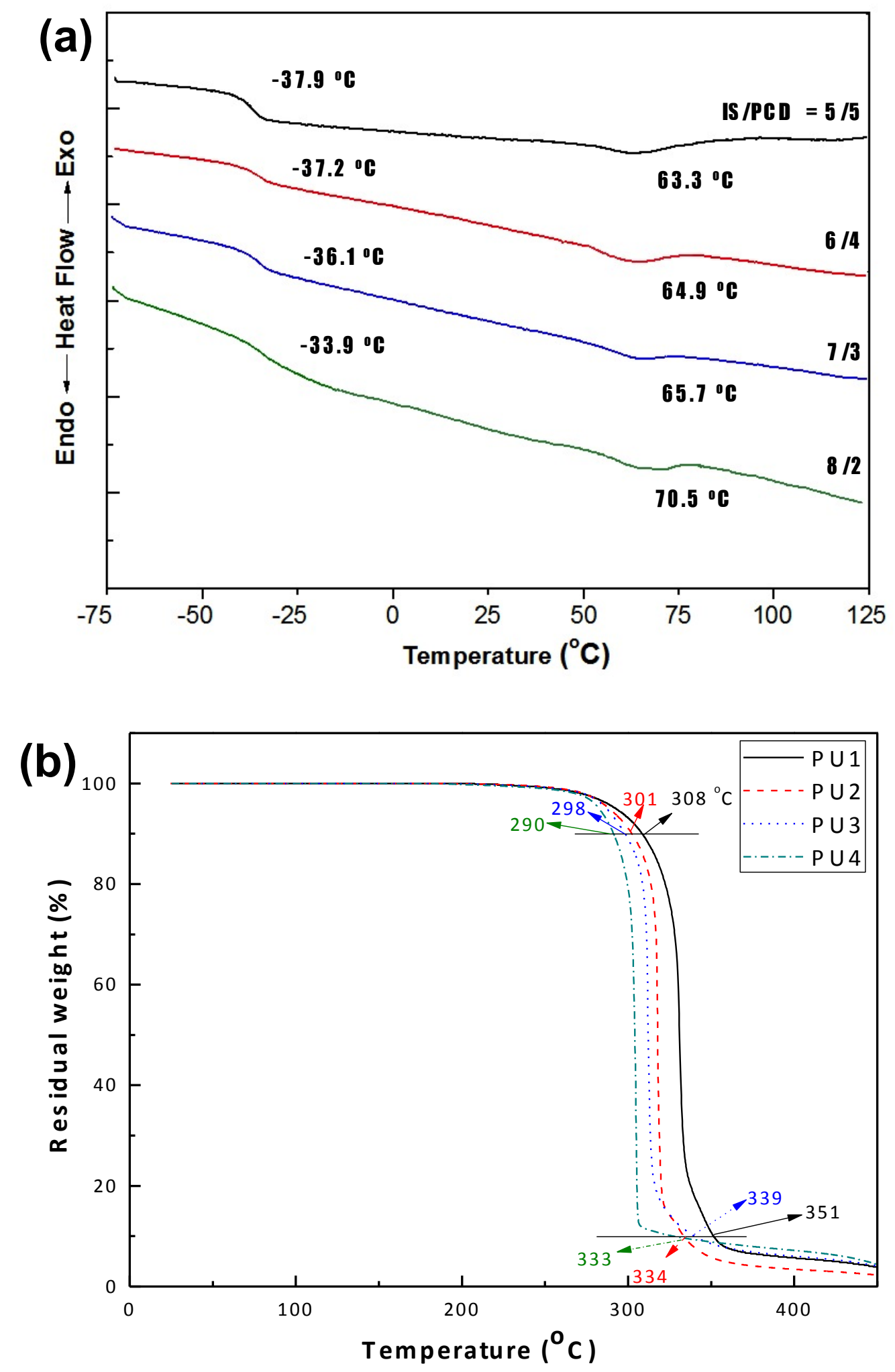

Figure 4. (a) DSC and (b) TGA thermograms of PCD/IS/HDI polyurethanes with different isosorbide and PCD contents. 
PCD: polycarbonate diol 2000; IS: isosorbide; HDI: hexamethylene diisocyanate.
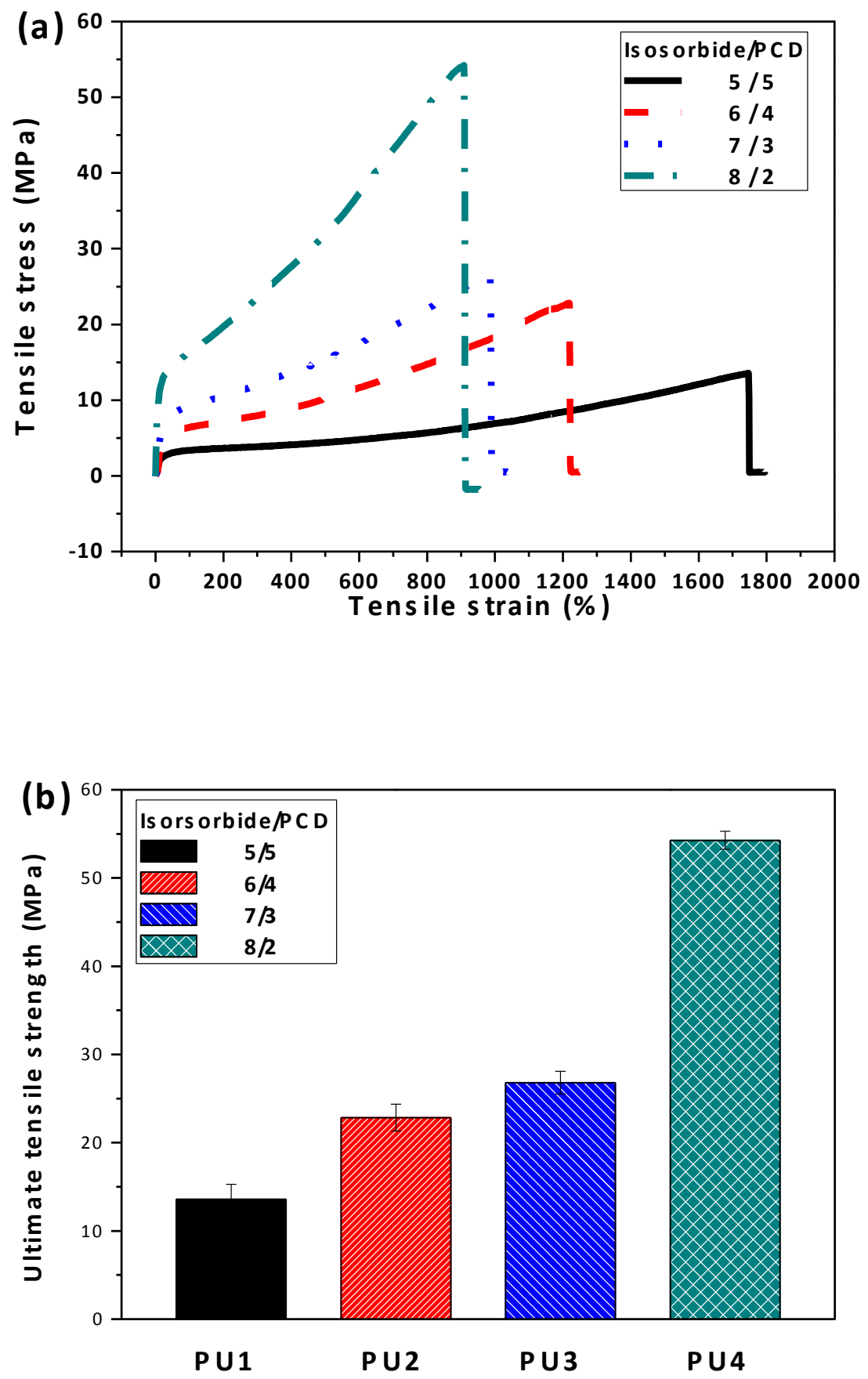

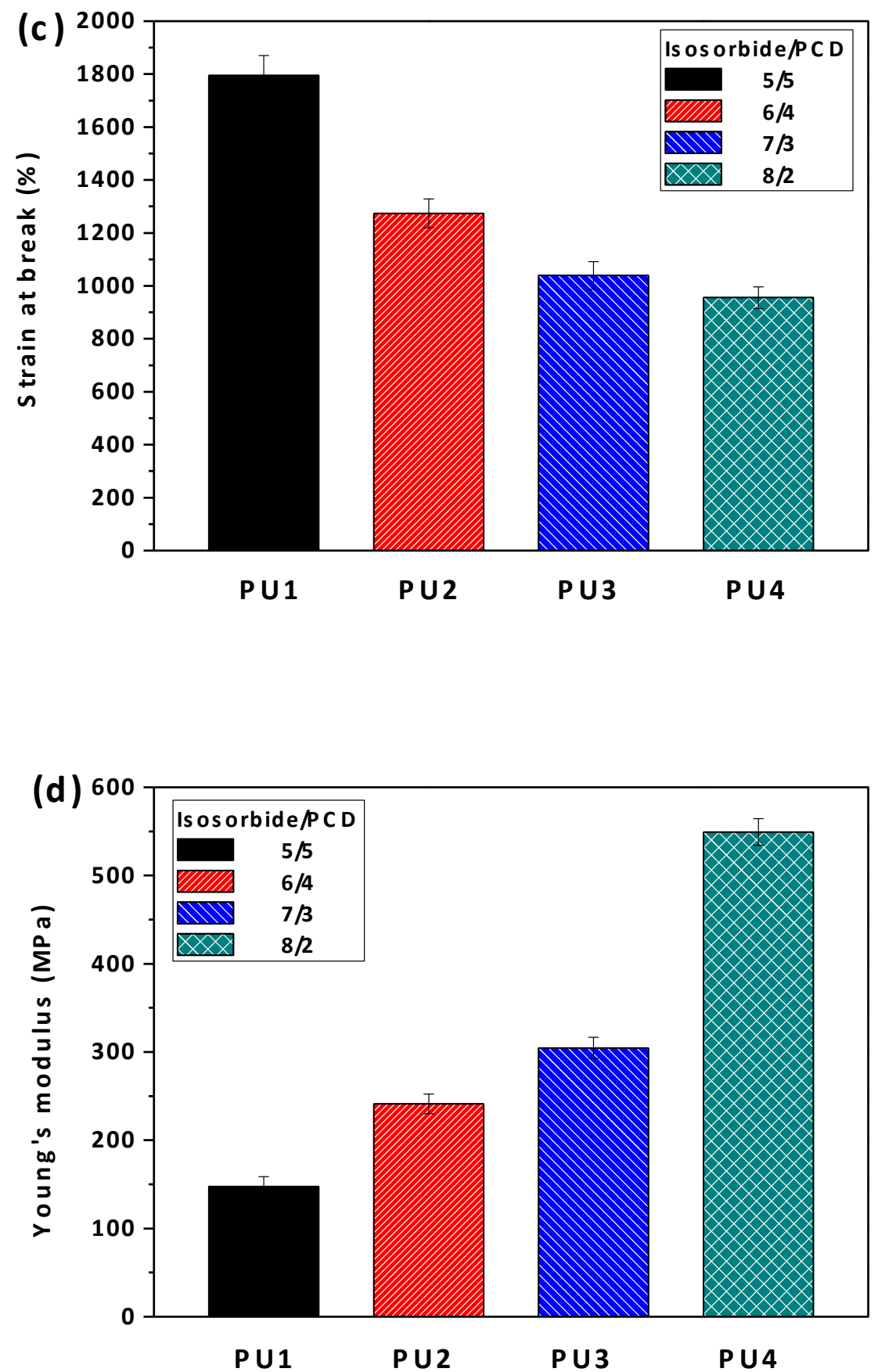

Figure 5. Mechanical properties of thermoplastic polyurethanes: (a) Tensile strain, (b) ultimate tensile strength, (c) strain at breaking and (d) Young's modulus. 


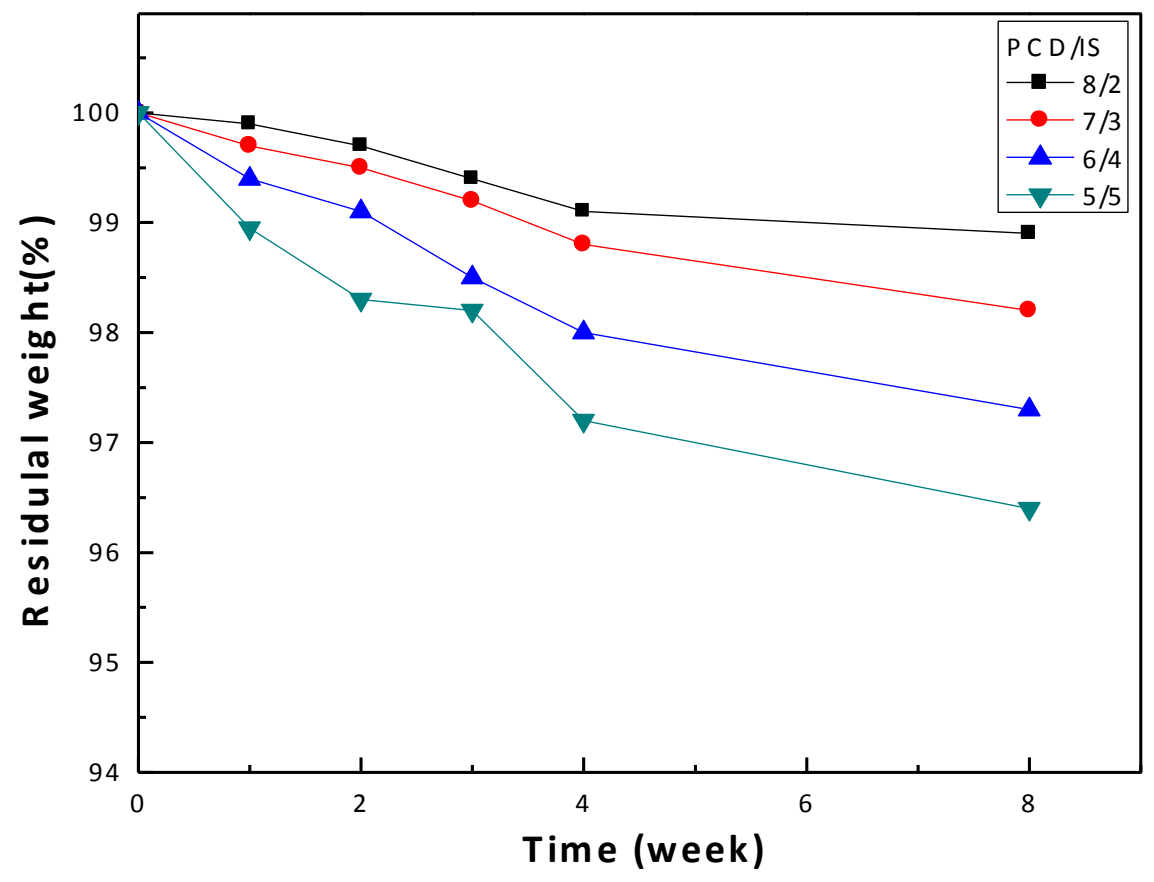

Figure 6. In vitro degradation profile of thermoplastic biocompatible polyurethanes as a function of degradation time vs. residual weight. 

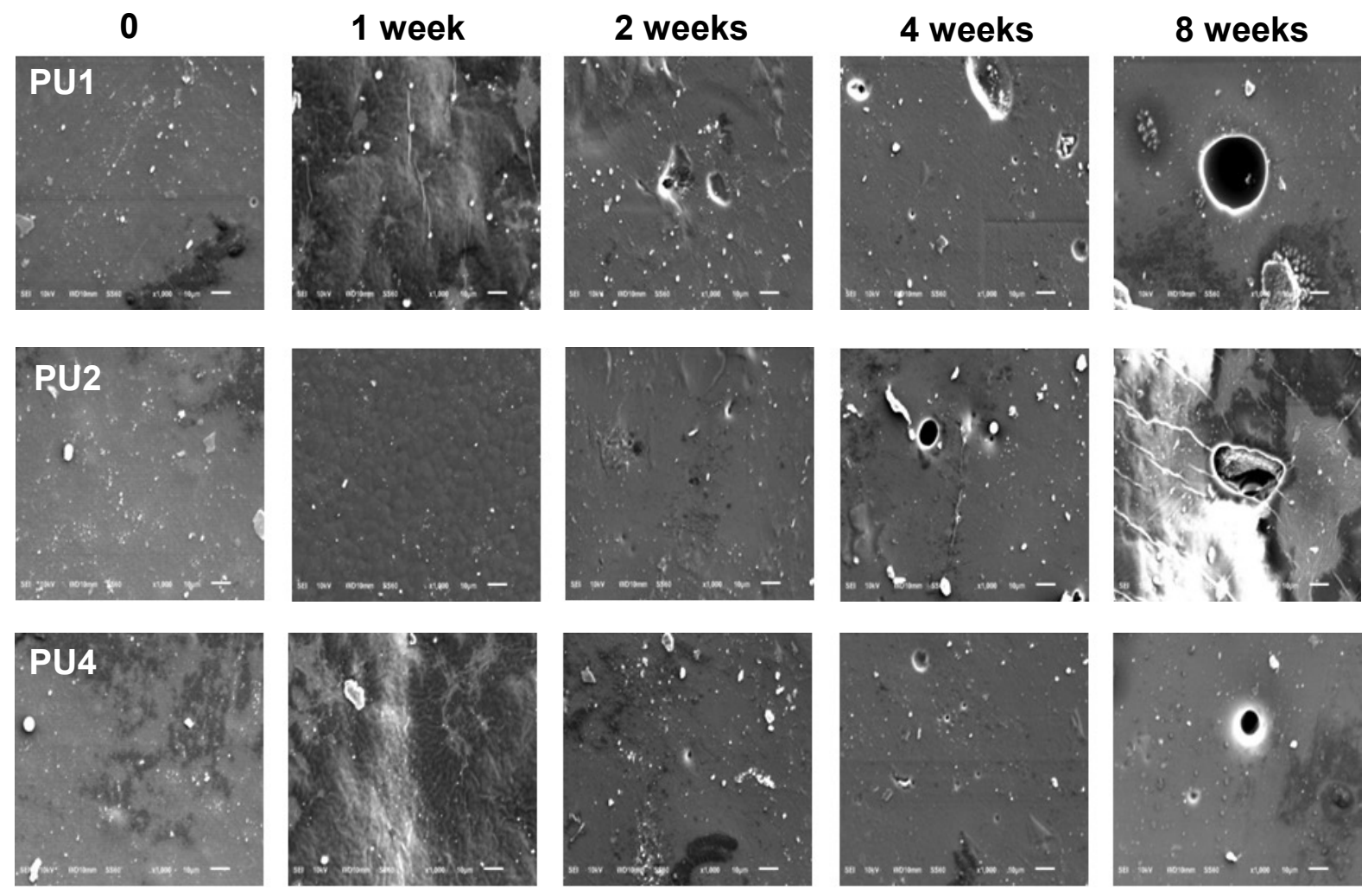

Figure 7. SEM images illustrating morphology of degradation test on polyurethane films in in phosphate buffer solution during 8 weeks. 


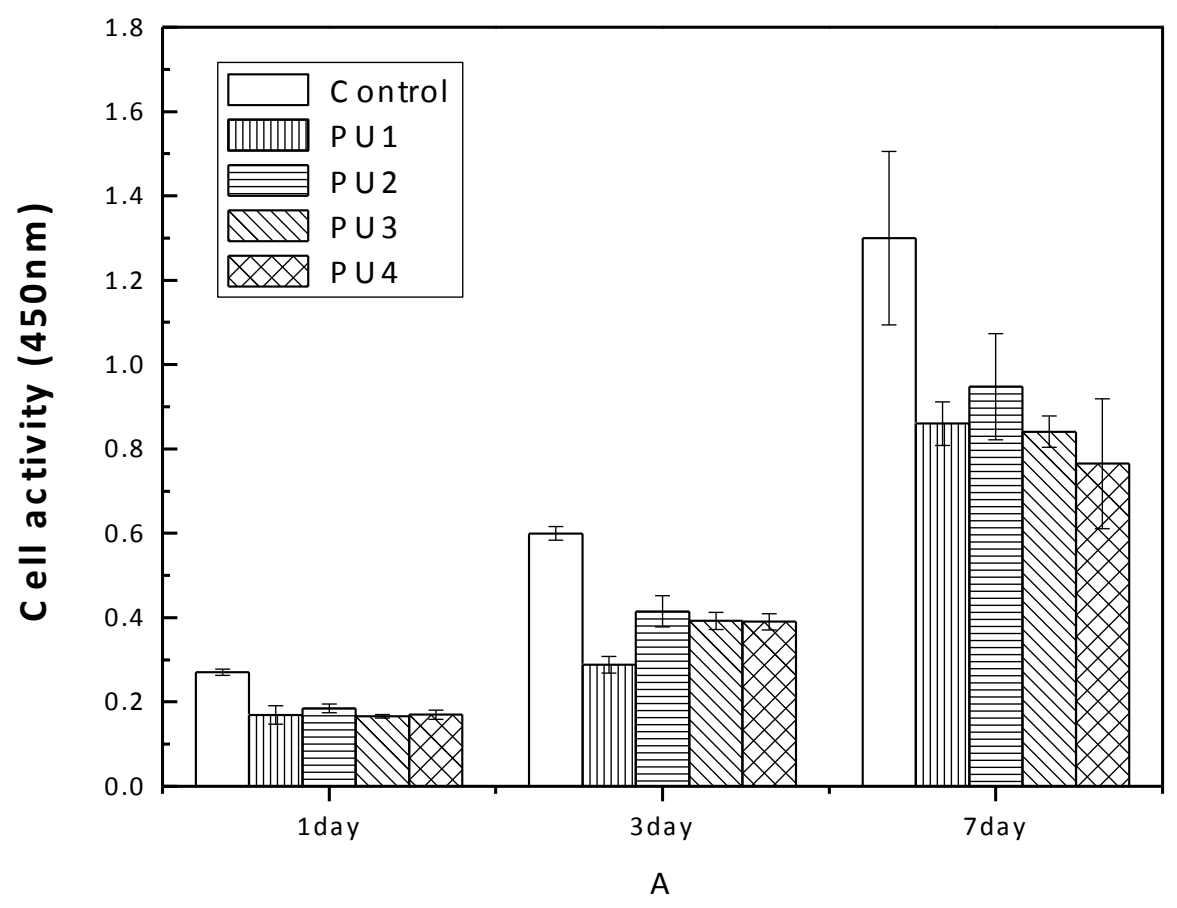

Figure 8. CCK assay of rat MC3T3-E1 cultured on polyurethanes wells during the 7 days. 

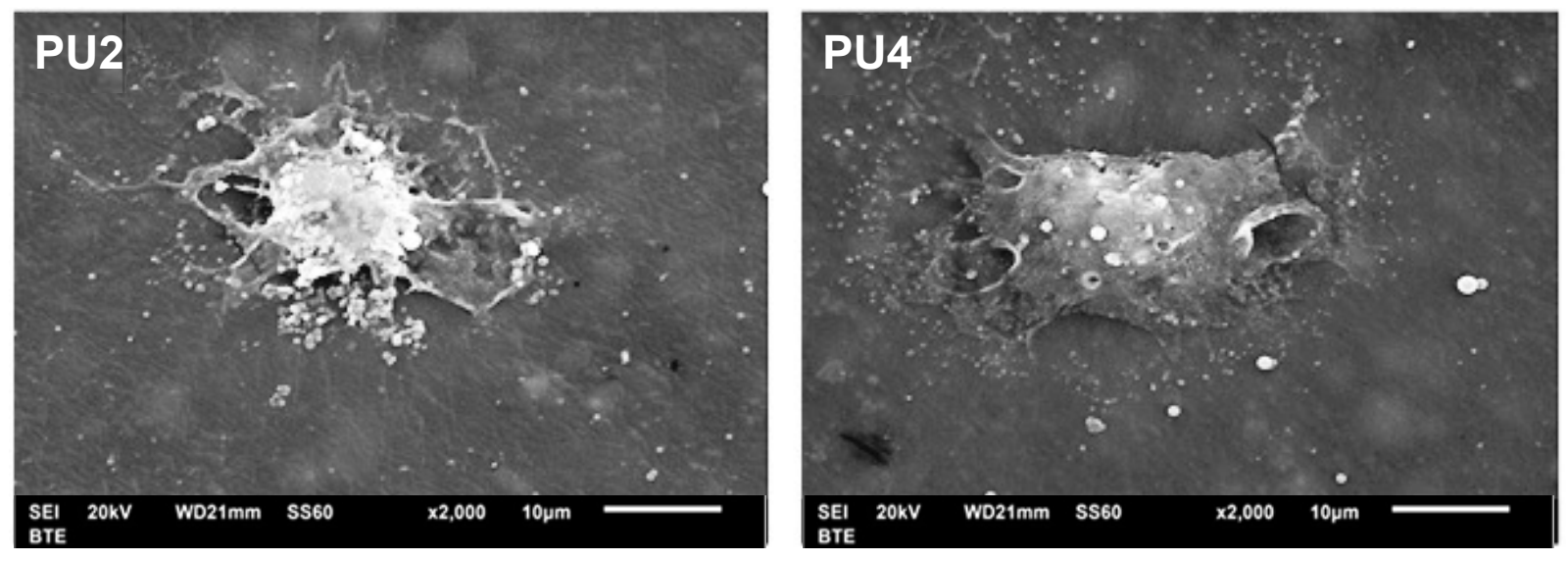

Figure 9. SEM images illustrating morphology of MC3T3-E1 cells after being cultured on polyurethane film at 7 day. 